\title{
Comparison of Human Resource Planning and Job Analysis process in banking sector of Pakistan
}

\author{
Abdul Waheed ${ }^{\star}$, Miao Xiaoming, Jawad Karamat, Salma Waheed \\ School of Management, Northwestern Polytechnical University, \\ Xi'an, 710072 Shannxi, P.R.China \\ waheed_2506@mail.nwpu.edu.cn
}

Keywords: Human Resource Planning, Job Analysis, Recruitment, Banking Sector.

\begin{abstract}
This paper gives an explanation about human resource(HR) practices in Bank Alfalah with the analysis in comparison to Faysal Bank, focus on banking sector to complete the task analysis of human resources management(HRM) practices and procedures for recruiting suitable employees, principles and procedures for monitoring employees and employee exit process from organization. 100 banks were targeted which respectively 50 for each and data was collected through interviews, influenced on Banking sectors. The main pillars human resources planning (HRP), job analysis, systematic recruitment and exit process is discussed. Essential motive of this research is to bring trained personnel in their setup to cope with the new challenges efficiently.
\end{abstract}

\section{Introduction}

A bank is a financial institution and intermediary that accepts deposits then put that deposits into lending activities, either directly or through capital markets. Bank is a critical status within the financial system and the economy generally and highly regulated in most countries. They are normally subject related to minimum capital requirements which are based on an international set of capital standards, known as the Basel Accords. For quick view the Pakistan's Banking Sector functions can be classified under the authorized broad categories which are State Bank of Pakistan, Nationalized Schedule Banks, Private Schedule Banks, Foreign Banks, Development/Cooperative/Investment Banks and Specialized Banks.

Human Resource Management is essential in all sectors and this research deals with human resources comparison in the banking sector of Pakistan. To run organizations process smoothly and effectively, the most preferable and indispensable factor organizations need is human resource [1]. In early stages Manpower planning, which was now called as Human resource planning was in the era of personnel management. The word human resource becomes familiar and got acceptance as a way of emphasizing the projective view of human resource. A proper human resource planning lead to the organization towards a good extends. The whole effectiveness of the organization completely depends upon the appropriate human resource planning. An effective human resource planning process analyzes the manpower needs under changing conditions and expansion activities [2].In this modern era where the world has become a global village, firms are considered to be competitive on the basis of the competence of their human resources. Studies have indicated that for performance to be optimal, an employee's full potential is needed at all levels in organizations [3]. Job analysis is invariably mentioned as a part of industrial/organizational activities, but the treatment rarely matches the acknowledged importance. While the amount of research on job analysis methods has increased dramatically in the past decade several critical issues remain unresolved [4]. More satisfied and happy employees would be more productive and profitable for the organization [5]. This research is concentrated upon the human resource management and its practices by two competitor banks Bank Alfalah and Faysal Bank. For this task, we focus on banking sector to complete the task analysis of 
HRM practices and procedures for obtaining suitable employees, principles and procedures for monitoring employees and employee exit process from organization.

\section{Comparison of Job Analysis and HR Planning process in Bank Alfalah and Faysal Bank}

The main objective of Bank Alflah is to develop and deliver the most innovative products which create difference from others, manage customer experience, relationship and deliver quality service that subsidizes to brand strength, establishes a comprehensive advantage and improves profitability, in this case providing value to the stakeholders of the bank. Bank Alfalah was established in 1997, it is first fully private bank and having fifth position in Pakistan banking sector. It has more than 480 branches across the country [6].Achieve leadership in providing financial services in chosen markets through innovation. Faysal Bank is a bank based in Pakistan. Faysal Bank Limited (FBL) was assimilated in Pakistan on October 3, 1994, as a public limited company under the Companies Regulation, 1984. Faysal Bank is integrated in Corporate, Commercial, Retail and Islamic Banking activities. It has more than 300 branches across the country [7].

\section{Research Methodology}

This study uses qualitative approach. Most of the data in this study was collected by Interview. This was done so that many details could be drawn out of the bank managers and employees. The interviews would give us an in-depth knowledge as to compare the HR planning and job analysis process in Bank Alfalah and Faysal bank. The qualitative method of research helps us in showing unanticipated findings and other descriptive data without assigning it numerical values. All the data was collected via interviews. This is because we were not getting any response via email. We have targeted 100 banks in which 50 respectively for each. The interviews were conducted with two different aspects. The first was about, what the banks think about the Human resource planning and job analysis process. Why the banks procedure are needed to make comparison of them. Secondly we asked about the targeted area of research recruitment and selection, exit, dismissal and redundancy process which build steps for comparison between Bank Alfalah and Faysal Bank.

\section{Human Resources planning (HRP)}

Human resource planning (HRP) is the unending continuous process of systematic planning to achieve optimal use of an organization's most valuable asset its human resources. The objective of human resource planning is to make sure the best fit between employees and jobs while avoiding staff shortages or surpluses. It involves predicting and planning for the acquisition, retaining, improvement and utilization of HR. Planning is very important part of any activity in organization, so every decision needs its own set of plans as there is a saying that "if you plan to fail, you plan to fail", process is the analysis of exiting workforce, the forecasted manpower, the development training, skills, abilities and capabilities [8].Fig.1 shows Human Resource Planning's in general practice.

\subsection{Job Analysis}

The job analysis data is be collected from incumbents through interviews or questionnaires, the creation of the analysis is a picture or specifications of the job, not a description of the person. Basic tools of job analysis are shown in Fig.2.Job analysis in Bank Alflah is based on administrative and managerial decisions are made in organization, such as recruitment, selection and training. The purpose of job analysis is: To collect information about the different level of activities will be performed, To gather information about education, skills, experience, personnel qualities, To select the suitable person for right job. Bestowing to our investigation and observation there are three different categories of jobs in the Faysal Bank which are treated and handled in different ways. Some policies of Faysal Bank human resource are different technically, but the overall HR practices, for example job analysis, Human resource planning and training are almost same. 


\subsection{Human Resource Planning in Banking Sector}

HR department is responsible for effective HR planning regarding demand and supply of employees and forecasting for these practices. The objective of human resources planning for Bank Alfalah is same like the other organization to forecast and plan for the acquisition, retention, improvement and utilization of HR. The bank managementlauthority make motivational plans to interlink the employee's goals with organization, encourage them and increase the performance of their employees. However in Fysal Bank the objectives, Defining skills required to meet the objectives effectively and efficiently, determine additional human resource requirement, Develop action to meet the anticipated HR need methods were used. By forecasting three things to enhance the employment plans which are Supply of inside candidates, Personnel needs and Supply from outside candidates according to the bank requirements.

\subsection{Comparison of Bank Alfalah and Faysal bank}

At Bank Alfalah the process of job analysis is conducted when the organization wants to open a new branch, setting up new technology or new services etc. The criteria of job description and specification are changed for each post. Although in Faysal Bank the process of job analysis is also conducted at any time it is needed for middle level staff. But there are no particular job criteria which followed for lower jobs. Such as high level management related job analysis is concerned, Bank Alfalah implements the universal process of recruitment for mutually internal and external sources according to the job criteria and specification given by the head office. Despite the fact in Faysal Bank the high level managerial post are mostly filled by the internal management from the persons with the required job specification and description by the head office.

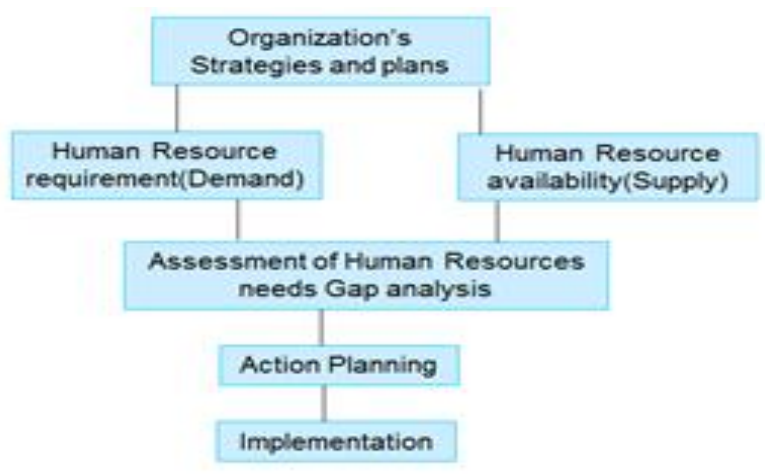

Fig.1Human Resource Planning (HRP)

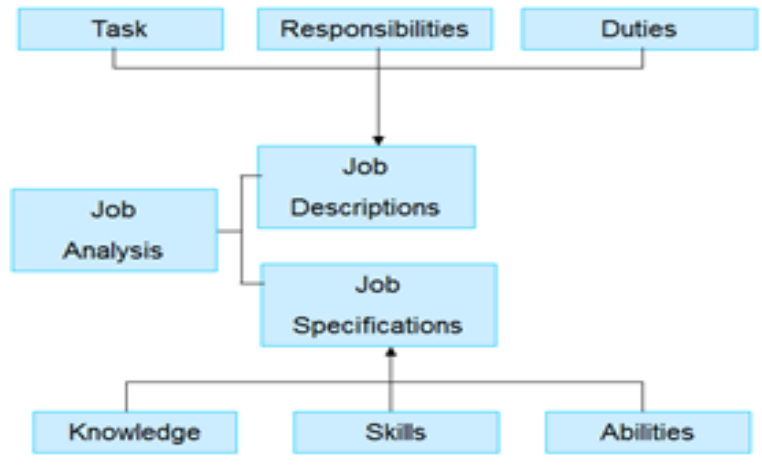

Fig.2 Job Analysis Basic Tool of HRM

\section{Recruitment}

Recruitment is the formal process of selection of employee. It is the systematic process of thorough the applicants for hiring and inspires them to apply for job in the organization. The overall aim of the recruitment process is to acquire the magnitude and eminence of employees to fill the vacant post of organization. Stages involve for Systematic approach of Recruitment, the process starts when the human resource branch receives requisition for recruitment from any department of the bank. A systematic approach of recruitment process involves these steps: Detailed HR planning, Job Analysis, Credentials of recruitment sources, Advertisement, Managing the response, Short-listing, Conducted Interviews.

Recruitment Sources (InfernalExternal)

Table 1 InfernalExternal Recruitment Sources [9]

\begin{tabular}{|l|l|l|}
\hline Sources & Advantages & Disadvantages \\
\hline Internal & $\begin{array}{l}\text { Boost up Moral of } \\
\text { employees, Incur }\end{array}$ & $\begin{array}{l}\text { Develop } \\
\text { Jealousy, Lack }\end{array}$ \\
\hline
\end{tabular}




\begin{tabular}{|l|l|l|}
\hline Recruitment & low cost. & of command \\
\hline External & $\begin{array}{l}\text { Bring qualified } \\
\text { Recruitment }\end{array}$ & $\begin{array}{l}\text { Longer process, } \\
\text { idea, Cheaper \& } \\
\text { faster than training } \\
\text { of expensive }\end{array}$ \\
& employees \\
\hline
\end{tabular}

\subsection{Selection Process}

Selection process involves screening of applicants by which best appropriate individual is picked for unoccupied post from a group of applicants. The other candidates rejected who are not found suitable as per the prescribe description and specification of job. The key objective of the selection process is that to choice the right individual for the right job. The selection process usually involves eight steps which are Preliminary Interview, Accomplishment of application form, Employment test, Comprehensive Interview, Contextual Investigation, Restricted Job offer, MedicaNPhysical Exam, Final Selection.

\subsection{Comparison of Recruitment and Selection process in Bank Alfalah and Faysal Bank}

As far as recruitment process from external sources and selection process is concerned, the method is same in the both the banks. The main change lies in the policy of human resource planning department. In the bank Alfalah all the process is finished with the consultation of managerial management at bank level although in the Faysal Bank the human resource department is fully authorized to take decision in creation of posts and recruitment on the unfilled post by themselves.

The internal sources recruitment process at advanced position is in practice and preferred Faysal Bank because of its low incurring cost. While in Bank Alfalah have a preference to recruit employee very educated and experienced person from outside at high cost since they think about the changing technology with all over the world, it is necessary to bring trained person in their setup to manage with the new challenges efficiently.

\section{Comparisons of Exit, Dismissal and Redundancy Procedure in Bank Alfalah and Faysal 6.1 Exit, Dismissal \& Redundancy Procedure in Bank Alfalah}

There are a number of steps involve in the exit procedure of Bank Alfalah which are Letter of resignation in written form, Process of resignation letter, Employee exit interview, Acceptance of resignation, Exit list check. In banks there are more possibilities of fraud in cash during different transactions. There is a proper procedure against employee dismissal which are If any employee found in the fraud of cash in bank then the bank will give him warning, After the warning letter the internal inquiry is held by the organization against that employee, This inquiry result will be sent to the higher management for further inquiry, If the fraud is proved on the worker then inquiry committee is established, When inquiry procedure is over then this committee make detail report on the employee, After this if the fraud is proved on the worker then dismissal letter is given to him and he will be dismissed from the job. Bank Alfalah is functioning under two types of redundancy. The compulsory redundancy candidate are most favorable candidates because these candidates serve more than 30 years for money, pension offer for future life and medical facilities to them. These candidates apart from the age of above 55 years and are also more favorable candidates for compulsory redundancy. In this case the employees are encouraged to do task in formal and good way in return they will be facilitated by a special package which is called Golden handshake. This package offers provident fund, medical benefit, monthly pension, car finance etc.

\subsection{Exit, Dismissal \& Redundancy Procedure in Faysal}

There are a number of steps involve in the exit procedure of Faysal Bank which are written resignation letter, Submit this resignation letter before the three months of resigning, Clear all the 
dues of organization, Acceptance of resignation letter. These are the steps of dismissal procedure of Faysal Bank which are Written warning given to the employee, Inquiry will conduct in the organization, A committee will made for high inquiry, If proved that such employee is involved in fraud or other informal work then dismissal letter given to him Ver, At the end helshe will dismissed. They are same like in Bank Alfalah. They are also observing two types of redundancy. Compulsory Redundancy, Non Compulsory Redundancy.

\subsection{Comparison}

There is no much big difference between exit, dismissal and redundancy process of organization which we selected. Most of the procedures are same in both banks but there is little bit difference in exit, dismissal while the redundancy procedure is same in both banks. The Bank Alfalah exit procedure is more complex as compare to Faysal Bank. They accept resignation of employee after a time consuming inquiry but Faysal Bank not does so mush inquiry in exit procedure.

\section{Conclusion}

Organizations exist when two or more people work together for achieving the common goals. An organization can never be better than the people it employed. Hence we have tried to get the best to have the best because the performance of the employees reflect the organization's image and standing in market to compete. Bank Alfalah is engaged in several business activities, various different techniques and methods that the management goes through in order to run this organization. It is important for Bank Alfalah to remain on top; it has adopted latest and up to date concepts technique of human resource management. They adopted such approaches that they have been able to preserve their employees happily and satisfied for so many years. This research has highlighted different aspects of human resource management i-e HR planning, job analysis, recruitment \& selection, exit and dismissal along with procedures that might be useful for Bank Alfalah HR management.

\section{References}

[1].Bushra, Fatima, Usman Ahmad, and Asvir Naveed. "Effect of transformational leadership on employees' job satisfaction and organizational commitment in banking sector of Lahore (Pakistan)." International journal of Business and Social science 2.18 (2011).

[2].Das, Pranaba Nanda, and Bandana Nayak. "Human Resource Planning in Nilachal Ispat Nigam Limited: Key to Ensure Effectiveness of the Organization." PARIPEX-Indian Journal of Research 4.11 (2016).

[3].Rothmann, S., and E. Coetzer. "The relationship between personality dimensions and job satisfaction." Business Dynamics 11.1 (2002): 29-42.

[4].Downes, Meredith, Iris I. Varner, and Masoud Hemmasi. "Individual profiles as predictors of expatriate effectiveness." Competitiveness Review: An International Business Journal 20.3 (2010): 235-24

[5].Saari, Lise M., and Timothy A. Judge. "Employee attitudes and job satisfaction." Human resource management 43.4 (2004): 395-407.

[6].www.bankalfalah.com, Introduction of Bank Alfalah

[7].www.faysalbank.com, Introduction of Faysal Bank

[8].BTEC(2001),HND Business: Human Resource Management: BBP Publishing

[9].Dessler, Gary, Gini Sutherland, and Nina Dawn Cole. Human resources management in Canada. Pearson Education Canada, 2005. 